\title{
Feed the gut, feed early and with the right stuff, but do not forget total parenteral nutrition
}

\author{
R. Latifi $\cdot$ S. Uranues
}

Received: 27 October 2012/Accepted: 30 January 2013/Published online: 5 March 2013

(C) Springer-Verlag Berlin Heidelberg 2013

Our recent article published in the European Journal of Trauma and Emergency Surgery [1] on nutrition support was widely downloaded by our readers, which gave the editors of the journal indications that there is a need for a focused issue on the nutrition support of trauma and critically ill patients. Professor Uranues and myself asked expert clinicians from different parts of the world to put together a number of articles that will shed light on the current principles and practices of the nutrition support of critically ill and injured patients. What we received are outstanding reviews of current evidence that we hope will serve clinicians around the world and, in particular, our trauma community to provide better care to our injured and critically ill patients. While nutrition support has changed dramatically in the recent two to three decades, it is imperative that, in order to improve our practice of nutritional support for trauma and critically ill patients, we should continue to pursue further understanding of their metabolism, energy requirements and specific requirements of each nutrient, and not rely on old dogma and guidelines established by experts' opinions and semi-quasi data. Specifically, we need to continue to challenge the current understanding of nutritional science, the biology of

R. Latifi $(\bowtie)$

Department of Surgery, University of Arizona, Tucson,

AZ, USA

e-mail: rlatifi@email.arizona.edu

R. Latifi

Trauma Services, Hamad General Hospital, Doha, Qatar

\section{S. Uranues}

Section for Surgical Research, Clinical Division of General

Surgery, Department of Surgery, Medical University of Graz,

Auenbruggerplatz 29, 8036 Graz, Austria

e-mail: selman.uranues@medunigraz.at nutrients and the interaction of these nutrients with trauma, injury and critical illness, and how to further advance timely and disease-directed nutritional support. In the meantime, we need to provide nutritional support to critically ill or injured patients early and we need to do it right [2], and we should tailor nutritional formulas based on the content of the nutrient compositions [3-5].

In the first article of this focus, Afifi et al. clearly demonstrate the evidence of significant metabolic changes that occur in critically ill and injured patients, and the need for supplementing key nutrients or special substrates to these patients in order to minimise the effect of trauma or critical illness. It has become obvious to all clinicians caring for these sick patients that one formula no longer fits all, as demonstrated by Yeah and Velmahos. To this end, there has been a significant paradigm shift in regard to selecting the appropriate nutritional strategy for critically ill and injured patients. In doing so, the nutrition support of patients with a particular disease is no longer regarded as a supportive measure; rather, it is regarded as direct nutritional therapy based on metabolic changes and on the biology of key nutrients induced by the disease process [4].

Both enteral nutrition as well as total parenteral nutrition are available in the physician's armamentarium, and there is no reason to starve any of our patients anywhere in the world or subject them to a number of complications that result from malnutrition and under-nutrition. Immunemodulating and immune-enhancing diets fortified with key nutrients such as glutamine, arginine, nucleotides, nucleosides, and antioxidants, vitamins and trace minerals, omega 3 fatty acids, branching amino acids and a large amount of vitamin $\mathrm{C}$ and other vitamins are available for clinical use today [5].

As described by Mazin et al., there are a number of techniques which enable access to the gastrointestinal tract 
of critically ill and injured patients, be it in the form of temporary or gastric tubes, or nasogastric or nasojejunal feeding tubes. More commonly though, in the majority of industrialised countries, in their hospitals, percutaneous endoscopic gastrostomy (PEG) is the technique of choice [6]. Other techniques such as laparoscopically assisted or complete laparoscopic gastrostomy and jejunostomy are certainly possible and practised around the world.

In the last article in this focus, Coimbra et al. review the current principles of feeding patients with open abdomen and damage control operation. Clearly, this particular segment of nutrition support has undergone significant changes. As demonstrated by the evidence provided in this article, these patients can, and should, be fed enterally.

In summary, we hope that this focus on the nutrition support of trauma and critically ill patients in our journal will help the practising surgeons review and update the current principles and practice in this important field.

We would like to take this opportunity to thank all the contributing authors for their outstanding job done in a relatively short period of time and, certainly, we would like to thank the editorial staff of the European Journal of
Trauma and Emergency Surgery for their persistence and assistance in completing this important task.

Conflict of interest None.

\section{References}

1. Joseph B, Wynne JL, Dudrick SJ, Latifi R. Nutrition in trauma and critically ill patients. Eur J Emerg Surg. 2010;36(1):25-30.

2. Latifi R. Editorial: nutritional support of critically injured patients: do it early and do it right. Eur Surg. 2011;43(1):5-6.

3. Latifi R. Nutritional therapy in critically ill and injured patients. Surg Clin North Am. 2011;91(3):579-93.

4. Dogjani A, Zatriqi S, Uranues S, Latifi R. Biology-based nutritional support of critically ill and injured patients. Eur Surg. 2011;43(1):7-12.

5. Con J, Joseph B, Kulvatunyou N, Tang A, O'Keeffe T, Wynne JL, Friese RS, Rhee P, Latifi R. Evidence-based immune-modulating nutritional therapy in critically ill and injured patients. Eur Surg. 2011;43(1):13-8.

6. Kulvatunyou N, Joseph B, Tang A, O'Keeffe T, Wynne JL, Friese RS, Latifi R, Rhee P. Gut access in critically ill and injured patients: where have we gone thus far? Eur Surg. 2011;43(1):24-9. 